\title{
Vanadium Inhalation in a Mouse Model for the Understanding of Air-Suspended Particle Systemic Repercussion
}

\author{
T. I. Fortoul, ${ }^{1}$ V. Rodriguez-Lara, ${ }^{1}$ A. Gonzalez-Villalva, ${ }^{1}$ M. Rojas-Lemus, ${ }^{1}$ \\ G. Cano-Gutierrez, ${ }^{1}$ M. Ustarroz-Cano, ${ }^{1}$ L. Colin-Barenque, ${ }^{2}$ L. F. Montaño, ${ }^{1}$ \\ I. García-Pelez, ${ }^{1}$ P. Bizarro-Nevares, ${ }^{1}$ N. Lopez-Valdez, ${ }^{1}$ C. I. Falcon-Rodriguez, ${ }^{1}$ \\ R. S. Jimenez-Martínez, ${ }^{1}$ M. L. Ruiz-Guerrero, ${ }^{1}$ L. S. López-Zepeda, ${ }^{1}$ \\ A. Morales-Rivero, ${ }^{1}$ and A. Muñiz-Rivera-Cambas ${ }^{1}$ \\ ${ }^{1}$ Departamento de Biología Celular y Tisular, Facultad de Medicina, UNAM, 04510 Mexico City, Mexico \\ ${ }^{2}$ Departamento de Neurociencias, FES Iztacala UNAM, 54090 Tlalnepantla, Mex, Mexico
}

Correspondence should be addressed to T. I. Fortoul, fortoul@servidor.unam.mx

Received 15 September 2010; Revised 11 February 2011; Accepted 8 March 2011

Academic Editor: Oreste Gualillo

Copyright ( $) 2011$ T. I. Fortoul et al. This is an open access article distributed under the Creative Commons Attribution License, which permits unrestricted use, distribution, and reproduction in any medium, provided the original work is properly cited.

\begin{abstract}
There is an increased concern about the health effects that air-suspended particles have on human health which have been dissected in animal models. Using CD-1 mouse, we explore the effects that vanadium inhalation produce in different tissues and organs. Our findings support the systemic effects of air pollution. In this paper, we describe our findings in different organs in our conditions and contrast our results with the literature.
\end{abstract}

\section{Vanadium as an Example of Chemical Components Adherent to Suspended Particles}

Airborne suspended particles (PM) consist of a heterogeneous mixture of solid and liquid particles suspended in air, continually varying in size and chemical composition in time and space. Primary particles are emitted directly into the atmosphere, such as diesel, whereas secondary particles are generated through physicochemical transformation of gases, such as nitrate and sulfate formation from gaseous nitric acid and sulfur dioxide $\left(\mathrm{SO}_{2}\right)$, respectively.

The numerous natural and anthropogenic sources of PM include motor vehicle emissions, tire fragmentation, power generation and other industrial combustion, smelting and other metal processing industries, agriculture, construction and demolition activities, residential wood burning, windblown soil, pollens and molds, forest fires and combustion of agricultural debris, volcanic emissions, and sea spray. Although there are numerous chemicals that have been detected in PM in different locations, some of the most common components include nitrates, sulfates, elemental and organic carbon, organic and biological compounds, and a variety of metals such as vanadium [1].

Vanadium is present in crude oil as an organic-metallic complex. The oil quantity of vanadium varies with the extraction source, finding important differences within countries; for example, Western Venezuelan and Maya Mexican oils have the highest concentrations of vanadium. Also in residual fuel oil, the concentrations are high (0.2 to $0.160 \mu \mathrm{g} / \mathrm{g}$ ). Coal is also rich in vanadium (14 to $56 \mathrm{mg} / \mathrm{kg}$ ). Natural sources also contribute to vanadium particulate concentrations in the atmosphere. Continental dust, volcanic eruptions, sea salt spray, and forest fires are some of the most productive genesis of vanadium [2].

\section{Generalities of Vanadium}

Vanadium, an outcome of the combustion of oil products, is inhaled adhered to suspended particles. Literature indicated that one of the main mechanisms of vanadium action is through the generation of reactive oxygen species (ROS), by the activation of mitogen activated protein kinases (MAPKs) that will result in the phosphorylation of downstream 


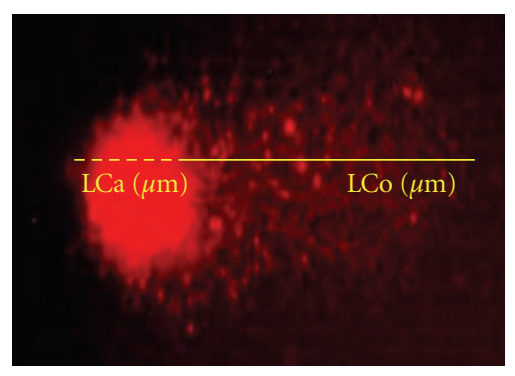

(a)

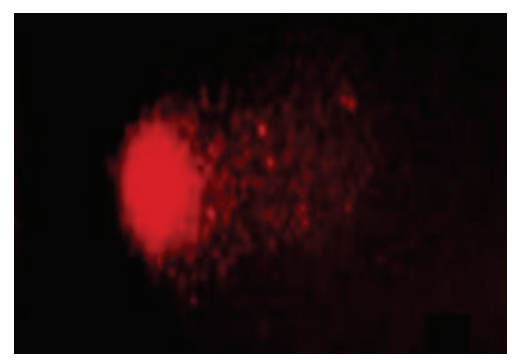

(d)

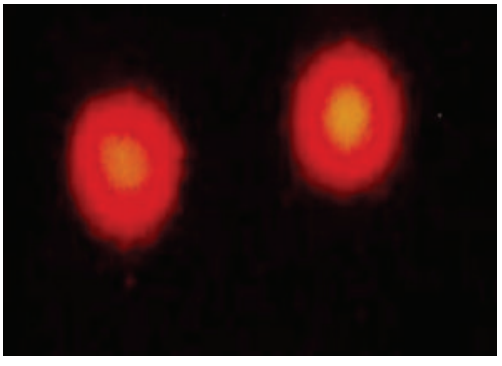

(b)

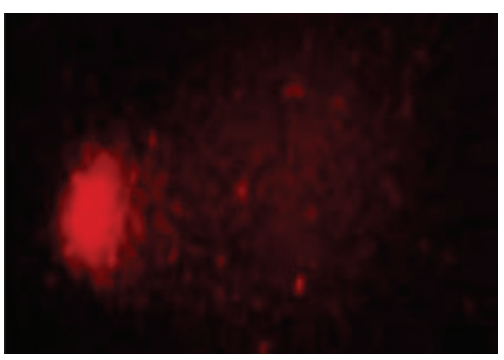

(e)

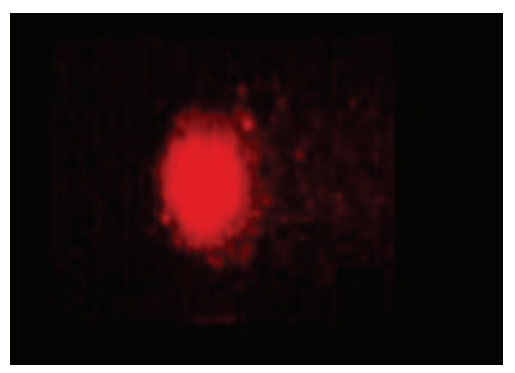

(c)

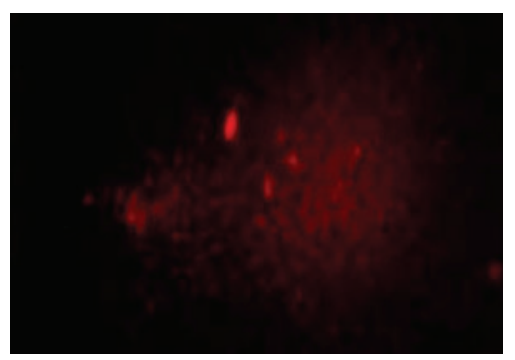

(f)

Figure 1: Comet classification. (a) Comet measurement, (b) no damage, (c) low damage, (d) medium damage, (e) high damage, and (f) total damage. The fluorochromization was performed with ethidium bromide and fluorescence microscope (1000x).

enzymes such as ERK1/2, resulting in the activation or deactivation of diverse signaling pathways.

Vanadium could also damage genetic material and induce hematotoxicity [3-5], immune toxicity [6], hepatotoxicity [7], lung toxicity [8-10], neurotoxicity [11-13], and reproductive toxicity [14-16] All these organs and systems are altered by vanadium inhalation, and in the next sections, we will describe the changes observed in our animal model, in an attempt to translate our findings to the actions that airsuspended particles could have on human health.

\section{An Animal Model to Assess Systemic Effects of Air-Suspended Particle}

Our model was evaluated in CD-1 mouse establishing a whole-body inhalation model $[11,17,18]$. The exposure schedule consisted of $\mathrm{V}_{2} \mathrm{O}_{5} 0.02 \mathrm{M}$ in saline, one hour twice a week. An ultranebulizer (UtraNeb 99 De Vilbis) with the size of the particle emitted being less than $5 \mu \mathrm{m}$ (range $0.5-$ $5 \mu \mathrm{m}$ ) at a flow rate of $10 \mathrm{~L} / \mathrm{min}$ was attached to a transparent acrylic box reaching stable concentrations in the chamber of $1436 \mu \mathrm{m} / \mathrm{m}^{3}$.

3.1. Genotoxicity. DNA damage is induced by exogenous agents such as environmental pollutants [19] or endogenous ones (free radicals) [20]. Genetic damage mechanisms include oxidation of nitrogenous bases or sugar residues; cross-links or DNA strand breaks [21, 22]. When DNA is altered, there are mechanisms for repairing the damage that could disrupt the strands and produce mutations or genetic material loss. Any agent that interacts with the genetic materials is dangerous [23] because the damage end result could be mitotic arrest, transcription gene induction, replicating errors, and genetic instability that could result in cancer $[22,24]$.

The adverse effects of vanadium on genetic material are controversial, contradictory, and scarce in vivo [25], and because of the scarce information available in the literature, IARC classifies vanadium as a $2 \mathrm{~B}$ category (possible human (arcinogen).

Single-Strand Breaks. Alkaline comet assay was used for the evaluation of single-strand breaks in peripheral leukocytes and bone marrow cells of exposed animals. This early genotoxic biomarker evaluates single-strand breaks [26]. With our model, we identify genotoxic damage in CD-1 mice which correlates with time of exposure. The greater the exposure, the longer the comet tails. With the same model, bone marrow was explored comparing male with female mice, and a clear difference was noticed in male mice, whose cells had greater damage (Figure 1).

Micronucleus. Micronucleus (MN) comprises aneugenic and clastogenic events in the cell that leads to chromosomal instability. The result of this type of genetic damage can induce cancer [27]. Applying Krishna and Hayashi [28] method to quantify MN in reticulocytes, we identified sexand age- (pre- and post-puberty mice) specific differences at 30, 60, and 90 days after the exposure had ended (Figure 2). Our findings indicate that adult females were the least affected. We suggest that estrogens as antioxidant molecules could be protecting females form reactive species produced by the interaction with vanadium $[29,30]$, but more research about these issues should be encouraged. 
3.2. Bone and Teeth Effects. Vanadium is concentrated in the bone inducing changes in its inorganic matrix density. Vanadium concentrations increased in the teeth with the time of exposure. The increased vanadium was associated with a decrease in the thickness of the teeth's enamel layer [31]. If the exposure is during teeth development, incisive histodifferentiation is altered resulting in ameloblast and predentin disorganization (Figures 3(a) and 3(b)).

These changes may explain the increased incidence of cavities in highly polluted areas as reported by Bowen [32].

\subsection{Hematopoietic System. Reports of vanadium hematotox-} icity are limited, and in many cases, contradictory. Some studies describe alterations in erythrocytes such as anemia, changes in hemoglobin and hematocrit concentrations [33$35]$, an increment in osmotic red blood cells fragility $[36,37]$, contrasting with other reports of microcytic erythrocytosis [38], and the acceleration of maturation on erythropoiesis [39]. Other researchers have found modifications in white blood cells count [33-35], contrasting with other reports of negative results in all hematologic parameters $[40,41]$. In the referred studies, the exposure route was oral or parenteral, with different vanadium compounds, but vanadium pentoxide inhalation, the principal source of exposure, has been poorly evaluated.

In subchronic vanadium exposure (eight-week inhalation), we found normochromic normocytic anemia, with a decrease in hemoglobin and hematocrit [3]. This anemia could be a consequence of hemolysis, as other researchers have proposed [36, 37], or might be a kind of erythrocyte suicide identified as eryptosis, specifically described for vanadium toxicity [42]; also an impairment of erythropoiesis could be assumed.

One of the most relevant findings in our model was the change on platelets. There was an increase in platelets counts (thrombocytosis) and morphological changes as megaplatelets [43]. This event was correlated with an increase of size and number of megakaryocytes (megakaryocytosis) in bone marrow and spleen $[4,44]$. There are no previous reports of thrombocytosis, but spleen megakaryocytosis is reported as a collateral finding by Al-bayati et al. in 1992 [45]. We consider that anemia may be a consequence of a detour from the bipotential progenitor cell (PEM) differentiation toward megakaryocytes and platelets instead of erythrocytes lineage, but this explanation needs further investigation. Thrombocytosis might be found as a reactive process or as a clonal event. There are some findings in our model such as the morphological changes of platelets (presence of megaplatelets) and megakaryocytes, accompanied with platelets functional impairment (data not published) that might suggest the presence of a clonal event known as essential thrombocythemia, but this hypothesis needs further analysis. Platelet production as a consequence of megakaryocyte proliferation depends mainly on thrombopoietin (TPO), and signaling pathways like JAK/STAT are required, so we are analyzing this pathway activation in our model [5].

Leukocytosis, with neutrophilia and lymphocytosis were observed in our model during the whole exposure. The same findings were reported in a study published by Zaporowska and Wasilewsky in 1992 [35]; however, they explored oral exposure. Fibrinogen and total serum proteins were also elevated [3]. These findings support a chronic inflammation state, and this could be also the explanation for thrombocytosis, but it does not explain changes in platelets and megakaryocytes function and morphology, so further research should be encouraged to understand these changes and to test the possibility of a clonal disorder.

3.4. Hepatotoxicity. Liver is also an inhaled vanadium target reporting that increased lipid peroxidation, evaluated by TBARS, is present during the exposure to this element. Applying another biomarker, 4-hydroxynonenal demonstrates that the hepatocytes' cell membrane is altered by oxidative damage. The oxidative destruction of polyunsaturated fatty acids in the membranes is the alteration that is developed as a positive staining for 4-hydroxynonenal, and the increase of TBARS. The histological evaluation of the liver in our model showed spotlights of inflammatory infiltrate. Other findings to be noted were an increase in the number of binucleated cells with meganucleus and modifications that suggest liver regenerative activity (Figure 4).

\subsection{Immune System}

3.5.1. Thymus. The thymus provides a variety of specialized microenvironments that support and direct T-cell differentiation and selection. Thymic microenvironment is delimited by a variety of cells such as macrophages, epithelial and dendritic cells (DC), fibroblasts, and immature $\mathrm{T}$ cells (thymocytes).

Dendritic thymic cells (DCs) are regularly distributed into the thymus medulla; they are a heterogeneous population of bone-marrow-derived immune cells, and differ in surface markers, migratory patterns, localizations and cytokine production. DCs are responsible for the negative selection of autoreactive $\mathrm{T}$ cells as discussed by $\mathrm{Wu}$ and Liu [46].

There are some reports that indicate the changes in the cortex-medulla thymic distribution as a consequence of $\mathrm{V}_{2} \mathrm{O}_{5}$ exposure as well as changes in cell populations' arrangement in a mice model. These changes suggest a modification in the CD's morphophysiology with possible health repercussion as discussed by González-Villalva et al. [43]. In the same experimental model we have been using, by immunohistochemistry for CD11c, we identify a decrease in color density for CD11c as the time of exposure increases (Figures 5(a) and 5(b)). This could be explained because of the vanadium oxidative potential, which generates reactive oxygen species (ROS); that could modify transcriptional factors associated with the inflammatory response as discussed by Gusik et al. [47].

3.5.2. Spleen. Vanadium exposure produces different effects on spleen such as splenomegaly, increase in megacaryocytes number and size, and the enlargement of the size of the white pulp, mainly because of the increase of CD19+ cells 


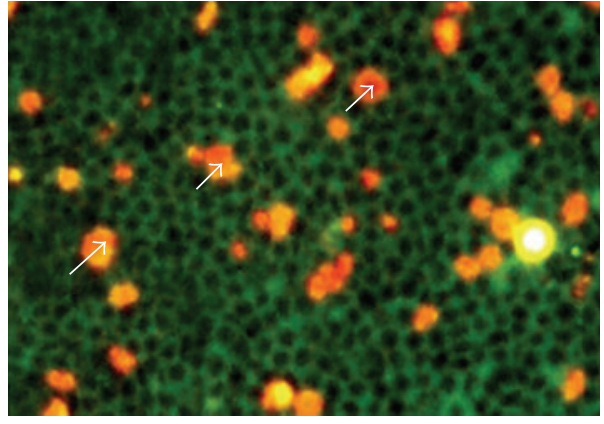

(a)

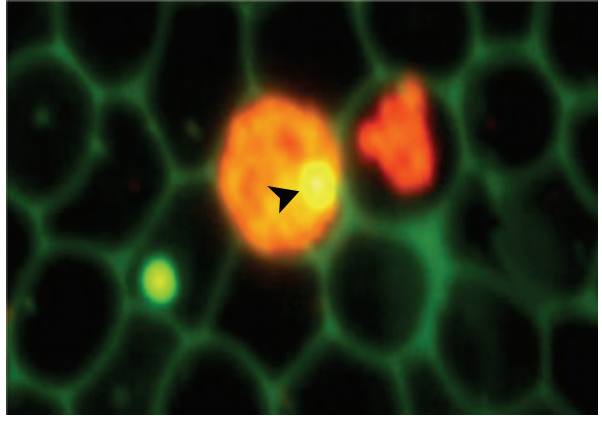

(b)

FIGURe 2: Micronucleus assay with mouse peripheral blood reticulocytes using acridine orange-coated slides. (a) Reticulocytes (white arrows) and erythrocytes (dark cells) (400x). (b) Micronuclei (head arrow) in reticulocyte (1000x).

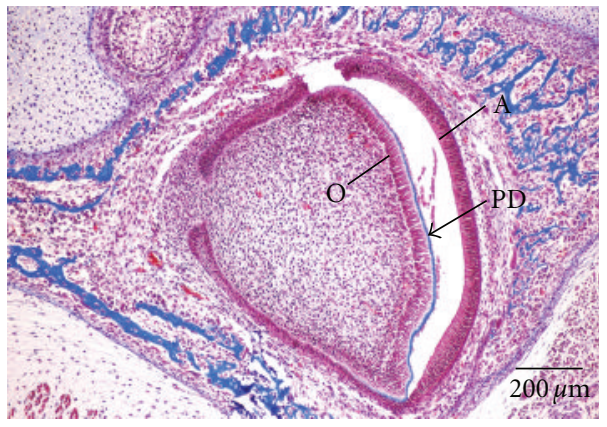

(a)

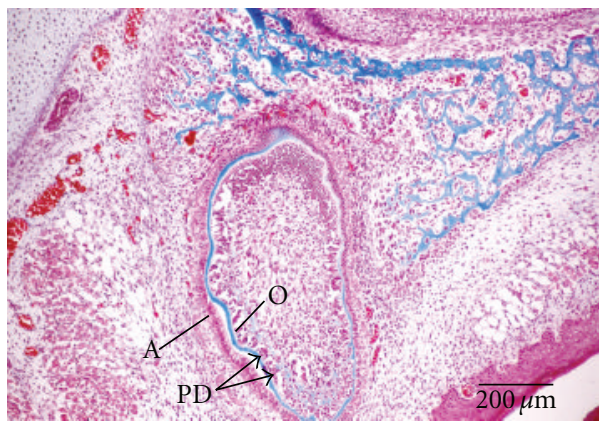

(b)

Figure 3: (a) Control dental primordium section from upper incisor with trichrome Masson stain. (A): Ameloblast. (O): Odontoblast. Predentine (PD). (b) Exposed dental primordium section from upper incisor with trichrome Masson stain. (A): Ameloblast. (O): Odontoblast. Predentine (PD).

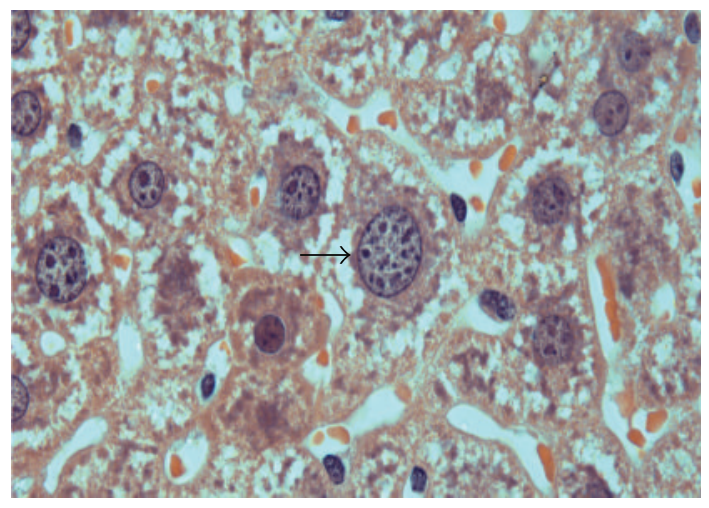

Figure 4: Meganucleated hepatocytes (arrow) were observed in the group of animals exposed to inhaled vanadium pentoxide. (400x).

(Figures 6(a) and 6(b)). Recently, it has been noted that these changes are due to an increment on the lymphocyte proliferation (Figures 7(a) and 7(b)).

Also we have observed nuclear changes in spleen lymphocytes and thymus after the first week of exposure and until three months of treatment. This could be due to a modification in the cytoskeleton and nucleoskeleton of these cells (Figures 8(a) and 8(b)).
3.5.3. Lymph Nodes. In lymph nodes, we observed that after 4 weeks of inhalation, there was an evident increase in the presence of CD25, a late lymphocyte activation marker. This was particularly true in the lymph node medulla, which contains primarily B cells. These findings match with what was observed in the spleen since, once again, B cells appear to be specially affected by vanadium (Figures 9 and 10).

3.6. Lung Toxicity. Adverse effects of vanadium in the lung have been associated to suspended particles air pollution exposure in humans, and experimental studies have been carried out in primates and rodents. These studies report that inhalation exposure results in impaired lung function, influx of inflammatory cells in bronchiolar lavage, and fibrotic changes in the lungs $[8,9,48]$.

In rats and mice exposed to $\mathrm{V}_{2} \mathrm{O}_{5}$ (whole-body), increases in inflammation and epithelial hyperplasia were observed at a $2 \mathrm{mg} / \mathrm{m}^{3}$ dose. In rats exposed to $4 \mathrm{mg} / \mathrm{m}^{3}$, fibrosis and a restrictive lung disease were observed [38].

In humans, accidental or inadvertent exposure to this compound in the workplaces has been associated with inflammatory responses in the respiratory tract, including bronchitis (often called boilermaker's bronchitis), pneumonia, rhinitis, and pharyngitis [49]. 


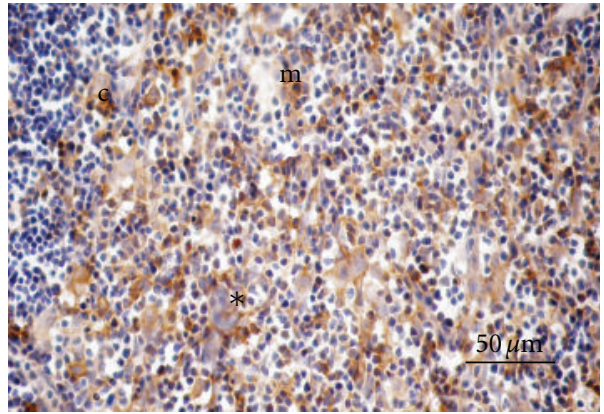

(a)

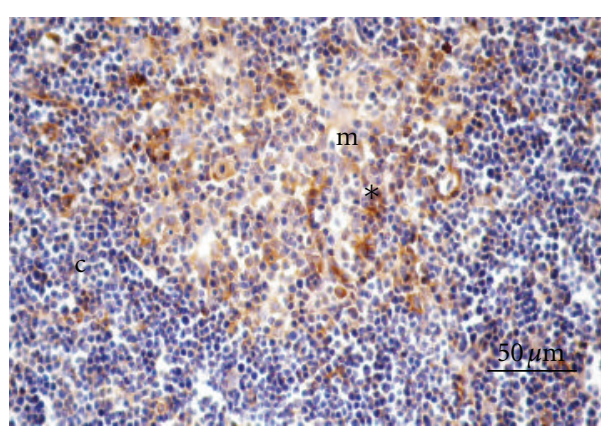

(b)

FIgure 5: (a) CD11c+thymic cells $(*)$ in control mice 2 week. Thymic cortex (c) and thymic medulla (m). (b) CD11c+ thymic cells $(*)$ in exposed mice 2 week. Thymic cortex (c) and thymic medulla (m).

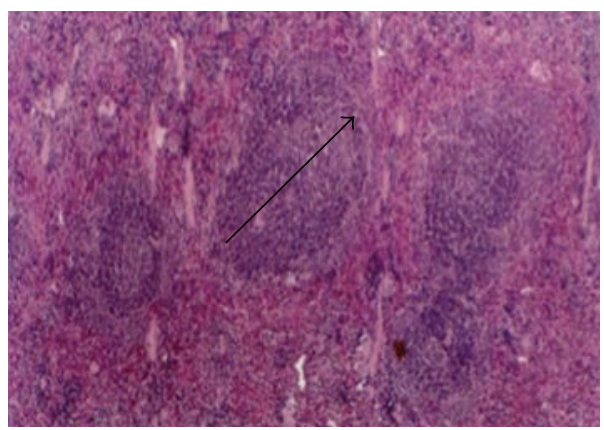

(a)

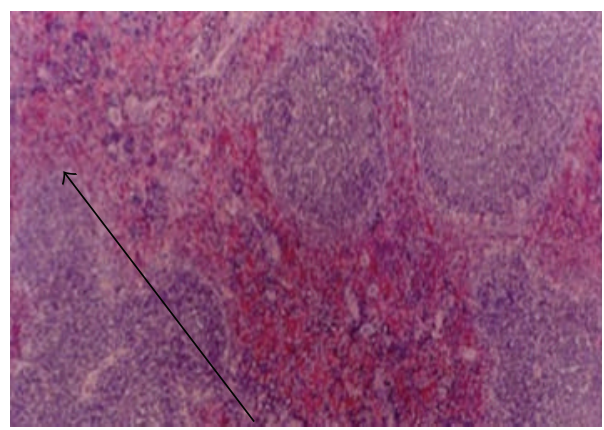

(b)

FIGURE 6: Enlargement of spleen lymphoid nodules due to $\mathrm{V}_{2} \mathrm{O}_{5}$ exposure. (a) Normal histology of spleen in control animals. (b) The growth of the white pulp mainly by lymphoid nodules (arrows) in the spleen from $\mathrm{V}_{2} \mathrm{O}_{5}$ that exposed animals is observed.

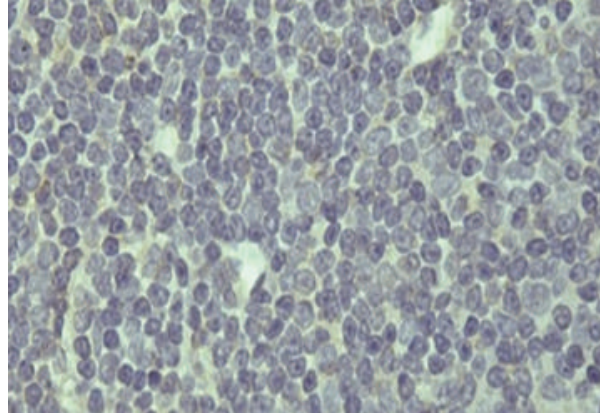

(a)

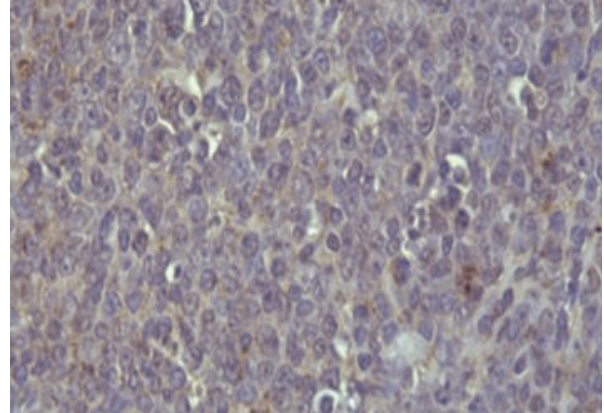

(b)

FIGURE 7: $\mathrm{V}_{2} \mathrm{O}_{5}$ effects on the lymphocyte proliferation index. In control spleen, a basal proliferation index is observed. (a) After vanadium exposure, the number of lymphocytes in division increased contrasting with control (b) (1000x).

In our model, the inhalation of vanadium caused an increase of cytokines such as IL- 6 and TNF- $\alpha$, located in the bronchiolar epithelium. This inflammatory response led to thickening of the bronchiolar muscular layer evaluated by alpha-actin immunohistochemistry [8]. This change was evidenced at 12-week exposure (Figure 11). The modifications found suggest airway remodeling similar to that observed in asthma [8].
Bonner and coworkers $[8]$ showed that rat intratracheal instillation with vanadium caused lung inflammation, airway hyperreactivity, fibroproliferative changes, mucus cell metaplasia, smooth muscle layer thickening, and airway fibrosis. However, we did not observe fibrosis in our inhalation model.

What we observed were changes in the nonciliated bronchiolar cell (NCBC) and ciliated cells nucleus that 


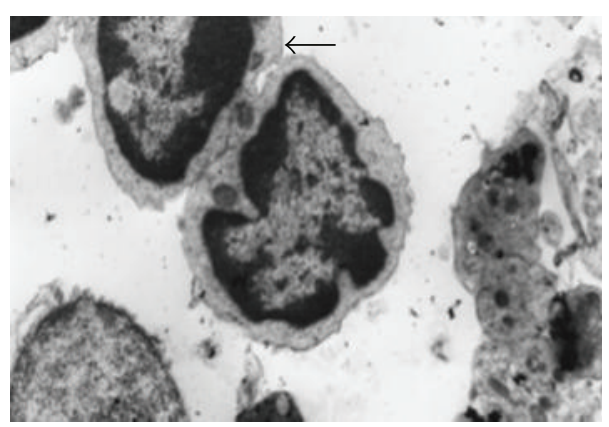

(a)

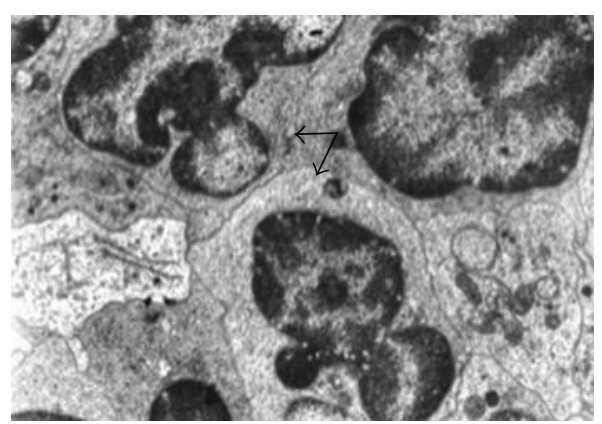

(b)

FIGURE 8: Spleen lymphocytes' nuclear changes after $\mathrm{V}_{2} \mathrm{O}_{5}$ exposure. (a) In control animal's nuclear morphology, regular ultrastructure in lymphocytes is observed (7000x) (arrow). (b) Vanadium exposure produces alterations in lymphocyte's nuclear morphology similar to the changes observed in malignant cells (8000x) (arrows).

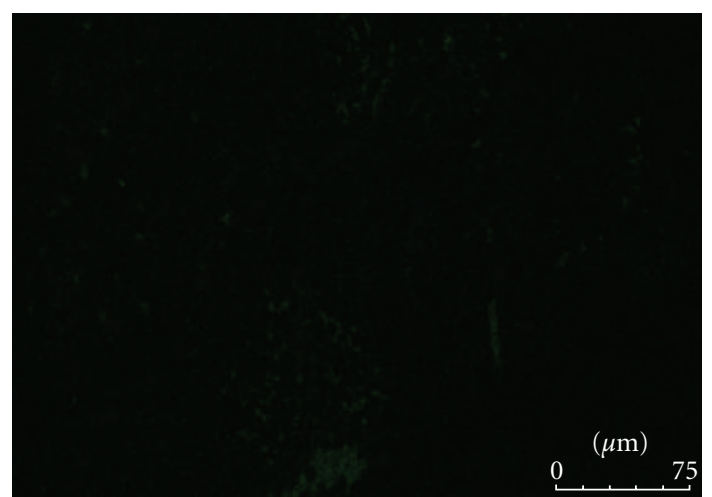

FIGURE 9: Immunofluorescence staining for CD25 in a lymph node medulla in a control mouse.

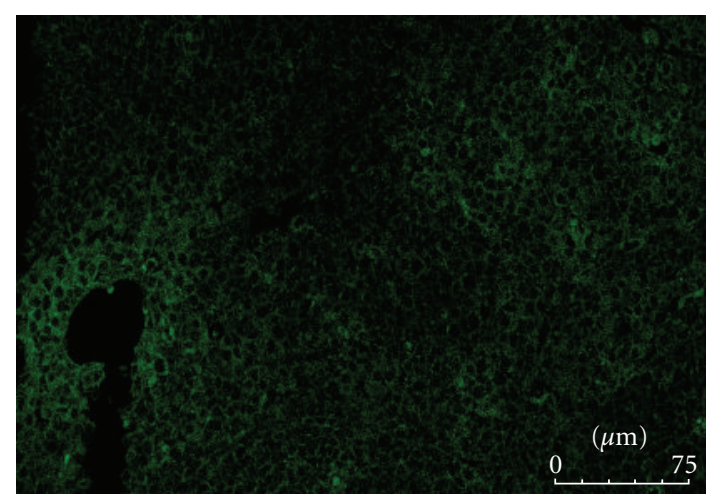

FIGURE 10: Immunofluorescence staining for CD25 in lymph node medulla after 4-week inhalation.

resembled pseudoinclusions [10]; also a decrease in the number of the NCBC was noticed [50].

3.7. Neurotoxicity. The central nervous system (CNS) exhibits a great vulnerability to oxidative stress damage, because of its continuous production of reactive oxygen species as a consequence of its high aerobic metabolism, low levels of antioxidants, and its extended surface rich in peroxidizable fatty acids which has been invoked as an excellent field for neuronal injury [51]. This damage might be expressed as neurodegenerative changes $[52,53]$.

In our mice model, vanadium induced functional, cytological, and ultrastructural alterations in the olfactory bulb, motor cortex (Figure 12(b)), hippocampus, striatum, substantia nigra, and ependyma [54]. In the olfactory bulb granule cells, spine density decreased at different times of exposure $(4,5,6,7,8,10$, and 12 weeks). In addition, lipofuscin granules, swelling organelles, vacuolation, and cytoplasmic condensation with disrupted mitochondria were recorded; apoptosis and necrotic neuronal deaths were also identified [54]. In our hands, these alterations were associated with olfactory dysfunction [55].

Our model showed nigrostriatal dopaminergic system damage that resulted in a decrease in the number of tyrosine hydroxylase immunoreactive neurons in the substantia nigra pars compacta and dendritic spine loss in the medium-sized spiny neurons of the striatum in exposed mice [12]. These changes might be the consequence of dopamine autooxidation resulting in quinones and semiquinones that may lead to substantia nigra cell death [56]. Oxidative damage, in our model, was confirmed by 4-hydroxynonenal (4-HNE) a lipid peroxidation marker by immunohistochemistry (Figure 12(d)). The damage observed in motor cortex neurons caused cell death, possibly by excitotoxicity with motor impairment [57].

In hippocampal formation, we observed morphological and functional alterations in the pyramidal neurons to CA1 and granule cells to dentate gyrus. A decrease in dendritic spines and pyramidal and granule cell necrosis were detected. These morphological alterations might correlate with spatial memory impairment $[13,58]$.

Blood-brain-barrier was also affected observing cilia loss in the fourth ventricle, as well as cell sloughing and dissolution of tight junctions between ependymal cells and basal membrane causing an evident disruption of the BBB [11]. These modifications were extended to the choroid plexus in lateral ventricles [57]. Additionally, an increase in gelatinases MMP-9 and MMP-2 activation in the olfactory bulb, prefrontal cortex, hippocampus, and striatum were 


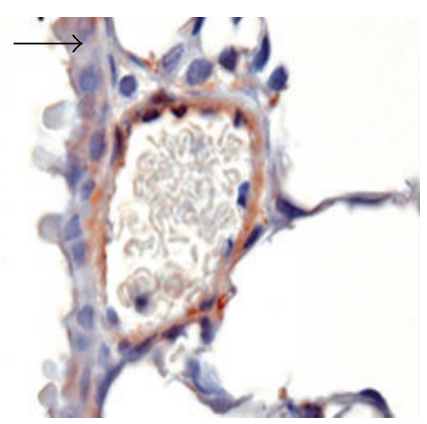

(a)

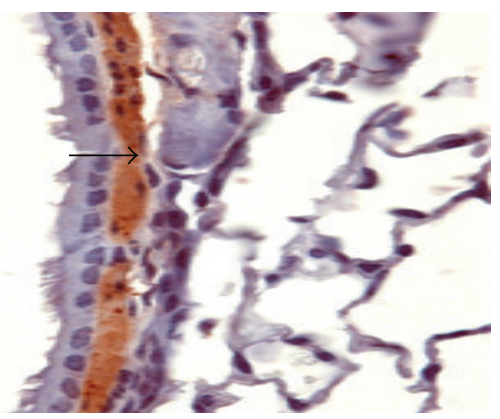

(b)

FIgure 11: Mouse bronchioles. (a) Normal bronchioles label with alpha-actin (arrows). (b) Thickening smooth muscle layer after 12-week exposure to vanadium. Original magnification 100x.

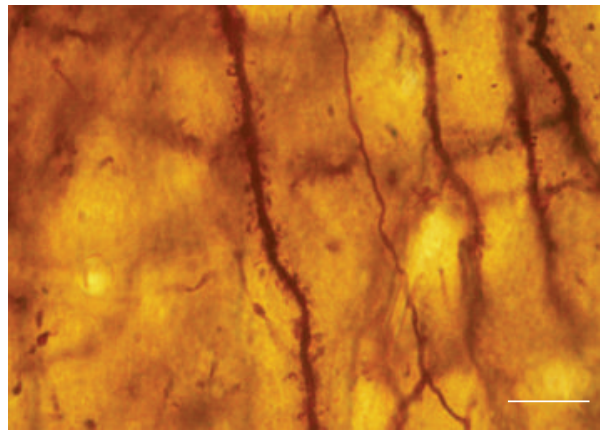

(a)

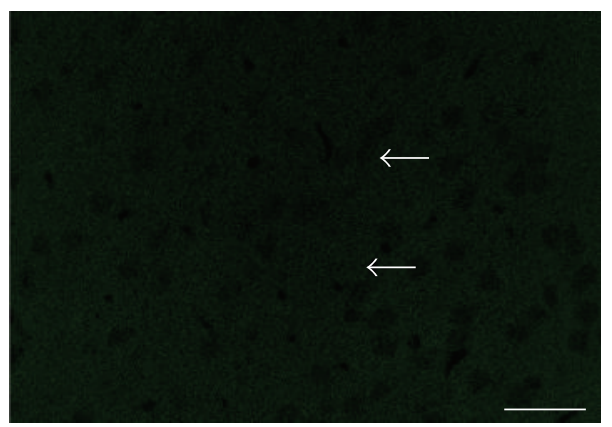

(c)

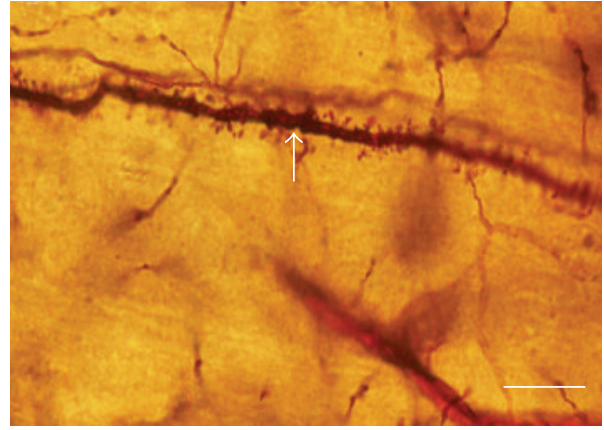

(b)

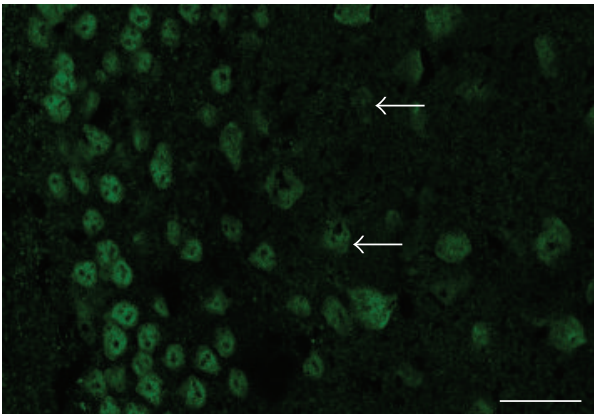

(d)

Figure 12: Photomicrograph of cortex pyramidal cells with Golgi stain. (a) Dendrite with spine dendrite in a control. (b) Exposure to vanadium, area with spine dendritic loss (arrow). (c) Image from a section of the cerebral cortex in control mice (confocal): the neuronal bodies (arrows). (d) Pyramidal cell neurons exposed to vanadium stained with 4-HNE (arrows). Scale bars: (a), (b) $10 \mu \mathrm{m}$; (c), (d) $50 \mu \mathrm{m}$.

observed [59], changes that could be associated to previously reported dendritic remodeling in the tissues [60] (Figure 12).

3.8. Reproductive Toxicity. The male reproductive system consists of the testes, their associated ducts, the accessory glands, and the penis. The testes produce sperm and testosterone. The seminiferous tubules are located in the testes [61], and the lining cells of the tubules comprise the seminiferous epithelium. Some of them are the source of sperm and some are there to sustain the production. The Sertoli or sustentacular cell helps the developing of sperm cells and defines the seminiferous tubule in two separate and physiologically different compartments, the basal and the luminal by occluding junctions of adjacent Sertoli cells. The seminiferous epithelium contains the sperm cells; the spermatogonium (stem cell) originates the sperm cells. These cells undergo meiosis and become haploid spermatocytes and spermatids, which further transform its complete morphological differentiation into spermatozoa [62].

Animal evidence demonstrates that i.p. vanadium treatment has adverse impacts on male reproductive health [14, $15,63]$. We compared the fine structure of seminiferous tubules in two groups of CD1 mice (experimental and control) [16], the experimental group underwent $\mathrm{V}_{2} \mathrm{O}_{5}$ inhalation at $0.02 \mathrm{M}$ for a 12 -week time period. Our studies 


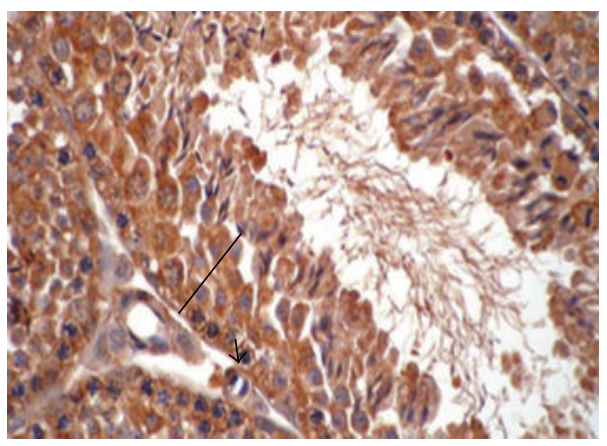

(a)

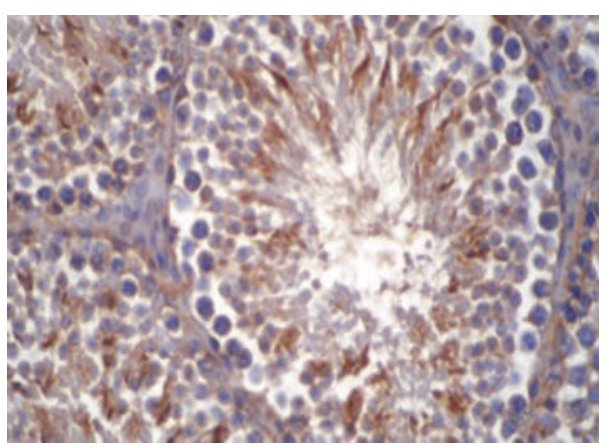

(b)

FIGURE 13: Actin Immunohistochemistry stain in seminiferous tubules. (a) Control animal showing positive immunoreactivity in Sertoli (arrow), Leydig (*) and germinal cells (clasp). (b) After six weeks of treatment the immunoreactivity decreased in all the testicular cells.

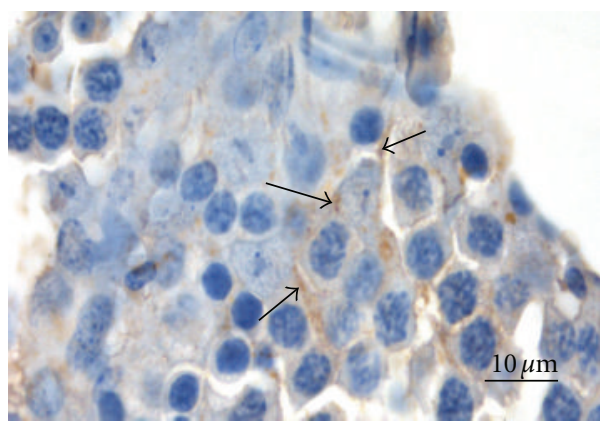

(a)

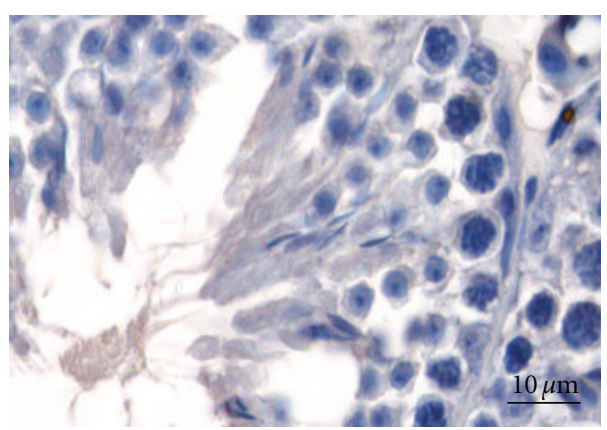

(b)

FIGURE 14: Immunohistochemical analysis for $\mathrm{Cx} 43$ localization in mice testes exposed for four weeks to $\mathrm{V}_{2} \mathrm{O}_{5}$ inhalation. (a) Cx43 in control mice was localized between Sertoli cells and germinal cells (arrows). (b) Cx43 immunostaining was absent in exposed mice.

demonstrated that $\mathrm{V}_{2} \mathrm{O}_{5}$ causes ultrastructural changes in testis of exposed mice. Ultrastructure examination revealed spermatogonia, spermatocytes, and Sertoli cells necrosis; the cells had obvious pathological changes including vacuolation cytoplasm and mitochondrial swelling, as well as decrease or vanish of mitochondria crista. Compared with the control group, the intercellular membranes of various seminiferous cells, as well as spermatozoa and Sertoli cells, were detached in the $\mathrm{V}_{2} \mathrm{O}_{5}$-exposed groups in a dose-dependent manner. In addition, other effects, such as pseudonuclear inclusions, were found.

Some toxic reproductive effects that were observed in this and other models, like alterations in spermatogenesis, low sperm count, decrease in sperm motility, and increase in the frequency of sperm morphologic abnormalities including morphological nuclear changes, suggest damage to the cytoskeleton [18].

Cytoskeletal proteins play an important role in the regulation of spermatogenesis and other process in the testis. Gamma-tubulin is a part of the cytoskeletal proteins and an important member of centrosome, which is the main microtubule-organizing center in animal cells. In a previous report, we observed that vanadium exposure decreased gamma-tubulin in Sertoli, Leydig and germinal cells in a time-dependent manner [18].
On the other hand, we have also observed that $\mathrm{V}$ is able to alter other cytoskeletal proteins like the actin in testicular cells. Actin is involved in different processes like cell division, cell morphological changes during differentiation, hematotesticular barrier integrity, and organization of testicular cells by junctional complex. Similar to tubulins, vanadium also alters actin in Sertoli, Leydig, and germinal cells in a time dependent manner. However, actin was less sensitive to the effect of vanadium than gamma-tubulin in testicular cells (Figure 13).

The damage to the cytoskeleton of testicular cells produced by vanadium implies changes in testicular functions leading to infertility, a phenomenon that has been implicated in vanadium exposure.

Metals also affect intercellular junctions by either reducing the amount of these or inducing aberrant intracellular localization of these membranous proteins [64]. Evidence indicates that these cell adhesion molecules are important as early targets for a variety of toxic substances including vanadium [65]. We used immunohistochemistry for localization of the gap-junctional proteins in Sertoli and spermatogenic cells, and Cx43 presence was observed essentially in the cell membrane of the basal compartment in control mice testis. Immunostained area revealed that there was a lack of membranous distribution of $\mathrm{Cx} 43$ and a shift from membranous 
immunoreactivity to predominantly cytoplasmic in exposed animals to $\mathrm{V}_{2} \mathrm{O}_{5}$ by four weeks [65] (Figure 14).

\section{Conclusions}

Atmospheric pollution repercussions by air-suspended particles are almost neglected. The use of animal models like the one described here helps to understand the interactions of the respiratory system, that is, the main entrance for air pollutants, and other organs such as the liver, reproductive system and nervous system. The increase in neurodegenerative diseases, infertility, and immune disorders needs a deeper evaluation for its possible link with air pollutants. These studies will support the reinforcement of atmospheric exposure limits worldwide.

\section{Acknowledgments}

The authors thank Raquel Guerrero Alquicira and Veronica Rodriguez-Mata for the technical support in the histological process for our work and Armando Zepeda Rodriguez and Francisco Pasos Nájera for the photographic work that was included in this paper. This work was partially supported by PAPPIT-UNAM IN 210409. L. S. Lopez Zepeda and A. Muñiz Rivera-Cambas are recipients of a junior investigator scholarship from the Sistema Nacional de Investigadores (SNI), CONACYT, Mexico.

\section{References}

[1] T. I. Fortoul and M. Rojas-Lemus, "Vanadium as an air pollutant," in Vanadium: Its Impact on Health, T. I. Fortoul and M. R. Avila-Costa, Eds., chapter 1, pp. 1-6, Nova Science, New York, NY, USA, 2007.

[2] N. Englert, "Fine particles and human health-a review of epidemiological studies," Toxicology Letters, vol. 149, no. 1-3, pp. 235-242, 2004.

[3] A. González-Villalva, A. Rodriguez-Lara, V. Montaño et al., "Blood changes generated after vanadium inhalation," Current Topics in Toxicology, vol. 6, pp. 31-38, 2009.

[4] T. I. Fortoul, G. Piñón-Zárate, M. E. Díaz-Bech et al., "Spleen and bone marrow megakaryocytes as targets for inhaled vanadium," Histology and Histopathology, vol. 23, no. 11, pp. 1321-1326, 2008.

[5] A. E. González-Villalva, C. I. Falcón-Rodríguez, and T. I. Fortoul, "Signaling pathways involved in megakaryopoiesis," Gaceta Médica de México, vol. 146, no. 2, pp. 136-143, 2010.

[6] G. Piñón-Zarate, M. Rojas-Lemus, E. Garcia- Zepeda, and T. I. Fortoul, "Metals and immune system," in Metals and Toxicological Implication in Health, T. I. Fortoul, Ed., chapter 5, pp. 43-64, Research Signpost, 2007.

[7] M. R. Avila-Costa and T. I. Fortoul, "Vanadium and the liver," in Vanadium: Its Impact on Health, T. I. Fortoul and M. R. Avila-Costa, Eds., chapter 8, pp. 57-74, Nova Science, New York, NY, USA, 2007.

[8] J. C. Bonner, A. B. Rice, C. R. Moomaw, and D. L. Morgan, "Airway fibrosis in rats induced by vanadium pentoxide," American Journal of Physiology, vol. 278, no. 1, pp. L209-L216, 2000.

[9] E. A. Knecht, W. J. Moorman, J. C. Clark, D. W. Lynch, and T. R. Lewis, "Pulmonary effects of acute vanadium pentoxide inhalation in monkeys," American Review of Respiratory Disease, vol. 132, no. 6, pp. 1181-1185, 1985.

[10] T. I. Fortoul, V. Rodriguez-Lara, P. Mussali-Galante, P. DiazBech, and L. F. Montaño, "Vanadium and respiratory system," in Vanadium Its Impact on Health, T. I. Fortoul and M. R. Avila-Costa, Eds., chapter 3, pp. 21-27, Nova Science, 2007.

[11] M. R. Avila-Costa, L. Colín-Barenque, A. Zepeda-Rodríguez et al., "Ependymal epithelium disruption after vanadium pentoxide inhalation: a mice experimental model," Neuroscience Letters, vol. 381, no. 1-2, pp. 21-25, 2005.

[12] M. R. Avila-Costa, E. D. Montiel Flores, L. Colín-Barenque et al., "Nigrostriatal modifications alter vanadium inhalation and inmunocytochemical and cytological approach," Neurochemical Research, vol. 29, no. 7, pp. 1365-1369, 2004.

[13] M. R. Avila-Costa, T. I. Fortoul, G. Niño-Cabrera et al., "Hippocampal cell alterations induced by the inhalation of vanadium pentoxide $\left(\mathrm{V}_{2} \mathrm{O}_{5}\right)$ promote memory deterioration," Neurotoxicology, vol. 27, pp. 1007-1012, 2006.

[14] A. K. Chandra, R. Ghosh, A. Chatterjee, and M. Sarkar, "Effects of vanadate on male rat reproductive tract histology, oxidative stress markers and androgenic enzyme activities," Journal of Inorganic Biochemistry, vol. 101, no. 6, pp. 944-956, 2007.

[15] M. A. Aragón, M. E. Ayala, T. I. Fortoul, P. Bizarro, and M. Altamirano-Lozano, "Vanadium induced ultrastructural changes and apoptosis in male germ cells," Reproductive Toxicology, vol. 20, no. 1, pp. 127-134, 2005.

[16] T. I. Fortoul, P. Bizarro-Nevares, S. Acevedo-Nava et al., "Ultrastructural findings in murine seminiferous tubules as a consequence of subchronic vanadium pentoxide inhalation," Reproductive Toxicology, vol. 23, no. 4, pp. 588-592, 2007.

[17] T. I. Fortoul, R. C. Salgado, S. G. Moncada et al., "Ultrastructural findings in the murine nonciliated bronchiolar cells (NCBC) after subacute inhalation of lead acetate," Acta Veterinaria Brno, vol. 68, no. 1, pp. 51-55, 1999.

[18] P. Mussali-Galante, V. Rodríguez-Lara, B. Hernández-Tellez et al., "Inhaled vanadium pentoxide decrease gamma-tubulin of mouse testes at different exposure times," Toxicology and Industrial Health, vol. 21, no. 9, pp. 215-222, 2005.

[19] J.-S. Taylor, "Unraveling the molecular pathway from sunlight to skin cancer," Accounts of Chemical Research, vol. 27, no. 3, pp. 76-82, 1994.

[20] T. Lindahl and R. D. Wood, "Quality control by DNA repair," Science, vol. 286, no. 5446, pp. 1897-1905, 1999.

[21] G. Slupphaug, B. Kavli, and H. E. Krokan, "The interacting pathways for prevention and repair of oxidative DNA damage," Mutation Research, vol. 531, no. 1-2, pp. 231-251, 2003.

[22] M. Valko, C. J. Rhodes, J. Moncol, M. Izakovic, and M. Mazur, "Free radicals, metals and antioxidants in oxidative stressinduced cancer," Chemico-Biological Interactions, vol. 160, no. 1, pp. 1-40, 2006.

[23] B. Halliwell and J. M. C. Gutteridge, "Oxygen toxicity, oxygen radicals, transition metals and disease," Biochemical Journal, vol. 219, no. 1, pp. 1-14, 1984.

[24] P. Møller, "Genotoxicity of environmental agents assessed by the alkaline comet assay," Basic and Clinical Pharmacology and Toxicology, vol. 96, no. 1, pp. 1-42, 2005.

[25] SCF, "Opinion of the scientific panel of dietetic products, nutrition and allergies on a request from the comission related to the tolerable upper intake level of vanadium," The EFSA Journal, vol. 33, pp. 1-22, 2004.

[26] P. Mussali-Galante, M. R. Ávila-Costa, G. Piñón-Zarate et al., "DNA damage as an early biomarker of effect in human 
health," Toxicology and Industrial Health, vol. 21, no. 7-8, pp. 155-166, 2005.

[27] S. Bonassi, A. Znaor, M. Ceppi et al., "An increased micronucleus frequency in peripheral blood lymphocytes predicts the risk of cancer in humans," Carcinogenesis, vol. 28, no. 3, pp. 625-631, 2007.

[28] G. Krishna and M. Hayashi, "In vivo rodent micronucleus assay: protocol, conduct and data interpretation," Mutation Research, vol. 455, no. 1-2, pp. 155-166, 2000.

[29] M. Badeau, H. Adlercreutz, P. Kaihovaara, and M. J. Tikkanen, "Estrogen A-ring structure and antioxidative effect on lipoproteins," Journal of Steroid Biochemistry and Molecular Biology, vol. 96, no. 3-4, pp. 271-278, 2005.

[30] D. Amantea, R. Russo, G. Bagetta, and M. T. Corasaniti, "From clinical evidence to molecular mechanisms underlying neuroprotection afforded by estrogens," Pharmacological Research, vol. 52, no. 2, pp. 119-132, 2005.

[31] T. I. Fortoul and M. L. Ruiz, "Bone and teeth effects," in Vanadium: Its Impact on Health, T. I. Fortoul and M. R. AvilaCosta, Eds., pp. 1-6, Nova Science, New York, NY, USA, 2007.

[32] W. H. Bowen, "Exposure to metal ions and susceptibility to dental caries," Journal of Dental Education, vol. 65, pp. 10461053, 2001.

[33] H. Zaporowska and W. Wasilewski, "Some selected peripheral blood and haemopoietic system indices in Wistar rats with chronic vanadium intoxication," Comparative Biochemistry and Physiology C, vol. 93, no. 1, pp. 175-180, 1989.

[34] H. Zaporowska and W. Wasilewski, "Haematological results of vanadium intoxication in Wistar rats," Comparative Biochemistry and Physiology C, vol. 101, no. 1, pp. 57-61, 1992.

[35] H. Zaporowska and W. Wasilewski, "Haematological effects of vanadium on living organisms," Comparative Biochemistry and Physiology C, vol. 102, no. 2, pp. 223-231, 1992.

[36] H. Zaporowska and M. Słotwińska, "Effect of vanadium on rat erythrocytes in vitro," Folia Histochemica et Cytobiologica, vol. 34, supplement 1, pp. 99-100, 1996.

[37] X. Yang, K. Wang, J. Lu, and D. C. Crans, "Membrane transport of vanadium compounds and the interaction with the erythrocyte membrane," Coordination Chemistry Reviews, vol. 237, no. 1-2, pp. 103-111, 2003.

[38] National Toxicology Program, "NTP toxicology and carcinogensis studies of vanadium pentoxide (CAS No. 1314-621) in F344/N rats and B6C3F1 mice (inhalation)," National Toxicology Program Technical Report Series, vol. 507, pp. 1-343, 2002.

[39] M. V. Aguirre, J. A. Juaristi, M. A. Alvarez, and N. C. Brandan, "Characteristics of in vivo murine erythropoietic response to sodium orthovanadate," Chemico-Biological Interactions, vol. 156, no. 1, pp. 55-68, 2005.

[40] S. Dai and J. H. McNeill, "One-year treatment of non-diabetic and streptozotocin-diabetic rats with vanadyl sulphate did not alter blood pressure or haematological indices," Pharmacology and Toxicology, vol. 74, no. 2, pp. 110-115, 1994.

[41] J. P. Fawcett, S. J. Farquhar, T. Thou, and B. I. Shand, "Oral vanadyl sulphate does not affect blood cells, viscosity or biochemistry in humans," Pharmacology and Toxicology, vol. 80, no. 4, pp. 202-206, 1997.

[42] M. Föller, M. Sopjani, H. Mahmud, and F. Lang, "Vanadateinduced suicidal erythrocyte death," Kidney and Blood Pressure Research, vol. 31, no. 2, pp. 87-93, 2008.

[43] A. González-Villalva, I. Fortoul Teresa, M. R. Avila-Costa et al., "Thrombocytosis induced in mice after subacute and subchronic V2O5 inhalation," Toxicology and Industrial Health, vol. 22, pp. 113-116, 2006.
[44] T. I. Fortoul, A. González-Villalva, G. Piñón-Zarate, V. Rodríguez-Lara, L. F. Montaño, and L. Saldivar-Osorio, "Ultrastructural megakaryocyte modifications after vanadium inhalation in spleen and bone marrow," Journal of Electron Microscopy, vol. 58, no. 6, pp. 375-380, 2009.

[45] M. A. Al-Bayati, M. R. Culbertson, J. P. Schreider, L. S. Rosenblatt, and O. G. Raabe, "The lymphotoxic action of vanadate," Journal of Environmental Pathology, Toxicology and Oncology, vol. 11, no. 2, pp. 83-91, 1992.

[46] L. I. Wu and Y. J. Liu, "Development of dendritic-cell lineages," Immunity, vol. 26, no. 6, pp. 741-750, 2007.

[47] J. Gusik, R. Korbut, and T. Adamek-Guzik, "Nitric oxide and auperoxide in inflammationand immune regulation," Journal of Physiology and Pharmacology, vol. 54, no. 4, pp. 469-487, 2003.

[48] J. C. Bonner, P. M. Lindroos, A. B. Rice, C. R. Moomaw, and D. L. Morgan, "Induction of PDGF receptor- $\alpha$ in rat myofibroblasts during pulmonary fibrogenesis in vivo," American Journal of Physiology, vol. 274, no. 1, pp. L72-L80, 1998.

[49] N. B. Ress, B. J. Chou, R. A. Renne et al., "Carcinogenicity of inhaled vanadium pentoxide in $\mathrm{F} 344 / \mathrm{N}$ rats and B6C3F 1 mice," Toxicological Sciences, vol. 74, pp. 287-296, 2003.

[50] T. I. Fortoul and C. I. Falcón-Rodríguez, "The lung and metals," in Metals ans Toxicological Implication in Health, T. I. Fortoul, Ed., chapter 7, pp. 71-79, Research Signpost, 2007.

[51] X. Wang and E. K. Michaelis, "Selective neuronal vulnerability to oxidative stress in the brain," Frontiers Aging of Neuroscience, vol. 2, pp. 1-13, 2010.

[52] D. Practicò and N. Delanty, "Oxidative injury in disease of the central nervous system: focus on Alzheimer's disease," American Journal of Medicine, vol. 109, no. 7, pp. 577-585, 2000.

[53] S. Nikam, P. Nikam, S. K. Ahaley, and A. V. Sontakke, "Oxidative stress in Parkinson's disease," Indian Journal of Clinical Biochemistry, vol. 24, no. 1, pp. 98-101, 2009.

[54] M. R. Avila-Costa, T. I. Fortoul, L. Colín-Barenque, J. Ordoñez-Librado, and A. Gutierrez-Valdez, "Vanadium and the Nervous System," in Vanadium: Its Impact on Health, T. I. Fortoul and M. R. Avila-Costa, Eds., pp. 29-42, Nova Science, 2007.

[55] M. H. Özdener and N. E. Rawson, "Olfactory dysfunction in neurodegenerative disease," European Journal of General Medicine, vol. 1, no. 3, pp. 1-11, 2004.

[56] Y. Luo and G. S. Roth, "The roles of dopamine oxidative stress and dopamine receptor signaling in aging and age-related neurodegeneration," Antioxidants \& Redox Signaling, vol. 2, no. 3, pp. 449-460, 2000.

[57] R. Jimenez- Martínez, Daño Oxidante en Corteza Cerebral y Plexo Coroideo de Ratones Expuestos a Pentóxido de Vanadio por Vía Inhalada, Tesis de Licenciatura. Universidad Nacional Autonoma de México, 2009.

[58] L. Colín-Barenque, M. R. Avila-Costa, M. Marínez et al., "Alteraciones ultraestructurales en giro dentado de ratones expuestos a la inhalación de Pentóxido de vanadio," Acta Microscopica, vol. 18, no. 3, 2009.

[59] L. Colín-Barenque, M. G. Martínez-Hernández, L. A. BaizaGutman et al., "Matrix metalloproteinases 2 and 9 in central nervous system and its modification after vanadium inhalation," Journal of Applied Toxicology, vol. 28, no. 6, pp. 718-723, 2008.

[60] A. Szlarczyk, J. Lapinska, M. Rylski, R. Mckay, and L. Kaczmarek, "Matrix metalloproteinase-9 urdergoes expression and activation during dendritic remodeling in adult 
hippocampus," Journal of Neuroscience, vol. 22, no. 3, pp. 920930, 2002.

[61] P. Bizarro and S. Acevedo, "Capítulo 15. Aparato reproductor masculino," in Biología Celular y Tisular, T. Fortoul and A. Castell, Eds., p. 265, McGrawHill, México, México.

[62] K. Caires, J. Broady, and D. McLean, "Maintaining the male germline: regulation of spermatogonial stem cells," The Journal of Endocrinology, vol. 205, no. 2, pp. 133-145, 2010.

[63] A. K. Chandra, R. Ghosh, A. Chatterjee, and M. Sarkar, "Amelioration of vanadium-induced testicular toxicity and adrenocortical hyperactivity by vitamin E acetate in rats," Molecular and Cellular Biochemistry, vol. 306, no. 1-2, pp. 189-200, 2007.

[64] W. C. Prozialeck, G. B. Grunwald, P. M. Dey, K. R. Reuhl, and A. R. Parrish, "Cadherins and NCAM as potential targets in metal toxicity," Toxicology and Applied Pharmacology, vol. 182, no. 3, pp. 255-265, 2002.

[65] S. O. Mikalsen and O. Kaalhus, "A characterization of pervanadate, an inducer of cellular tyrosine phosphorylation and inhibitor of gap junctional intercellular communication," Biochimica et Biophysca Acta, vol. 1290, no. 3, pp. 308-318, 1996. 


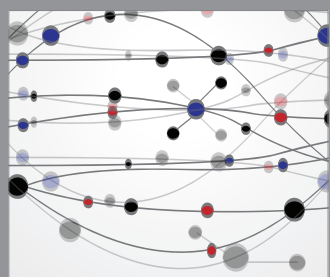

The Scientific World Journal
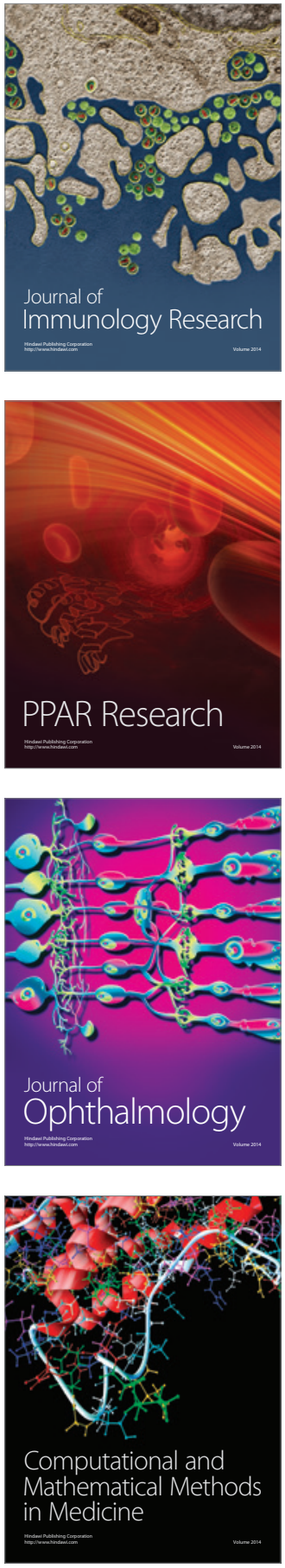

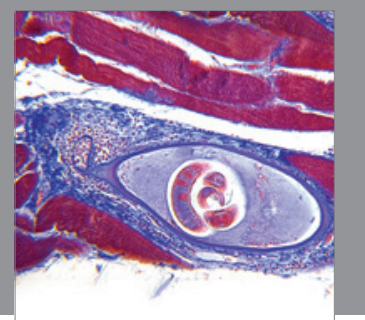

Gastroenterology

Research and Practice
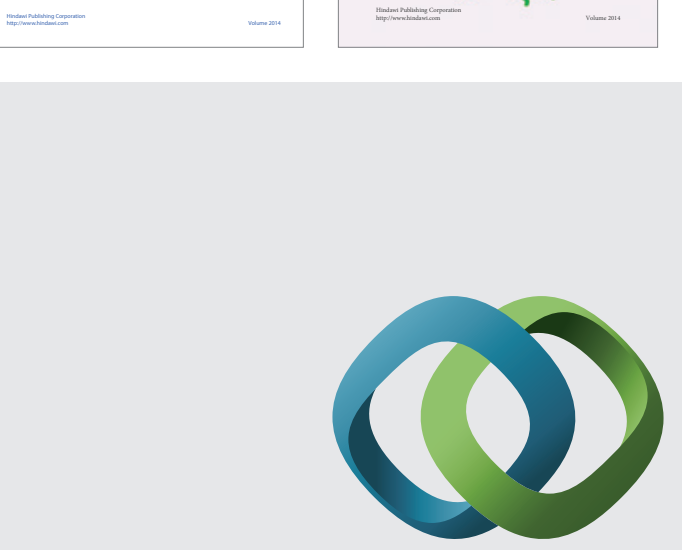

\section{Hindawi}

Submit your manuscripts at

http://www.hindawi.com
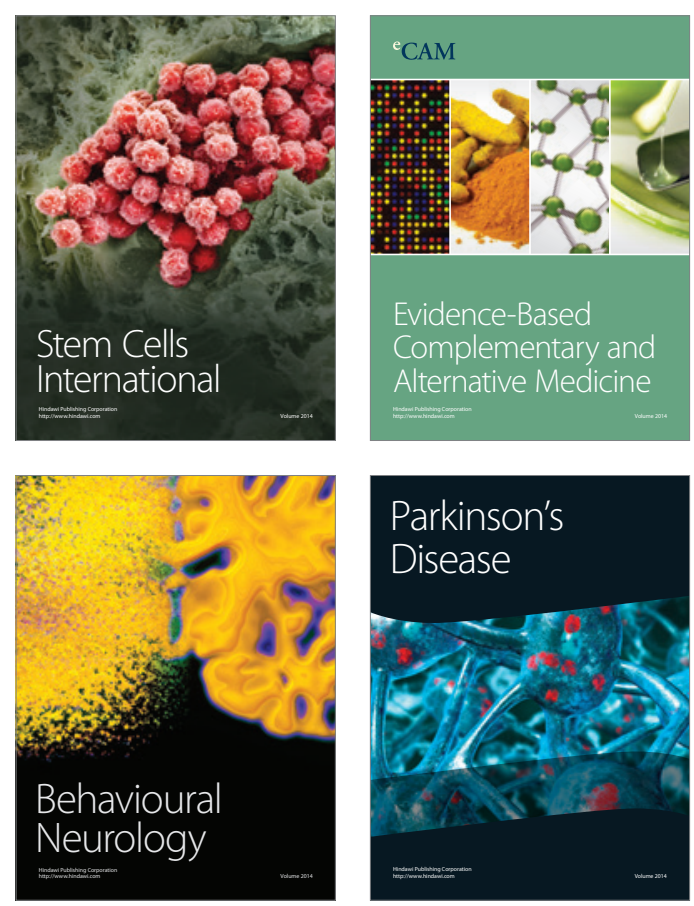

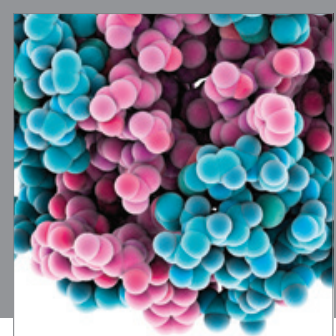

Journal of
Diabetes Research

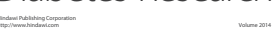

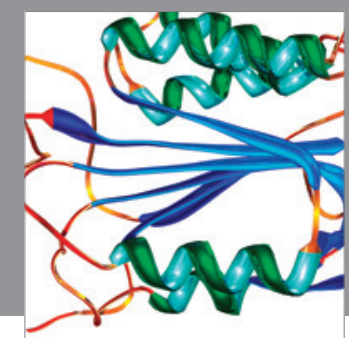

Disease Markers
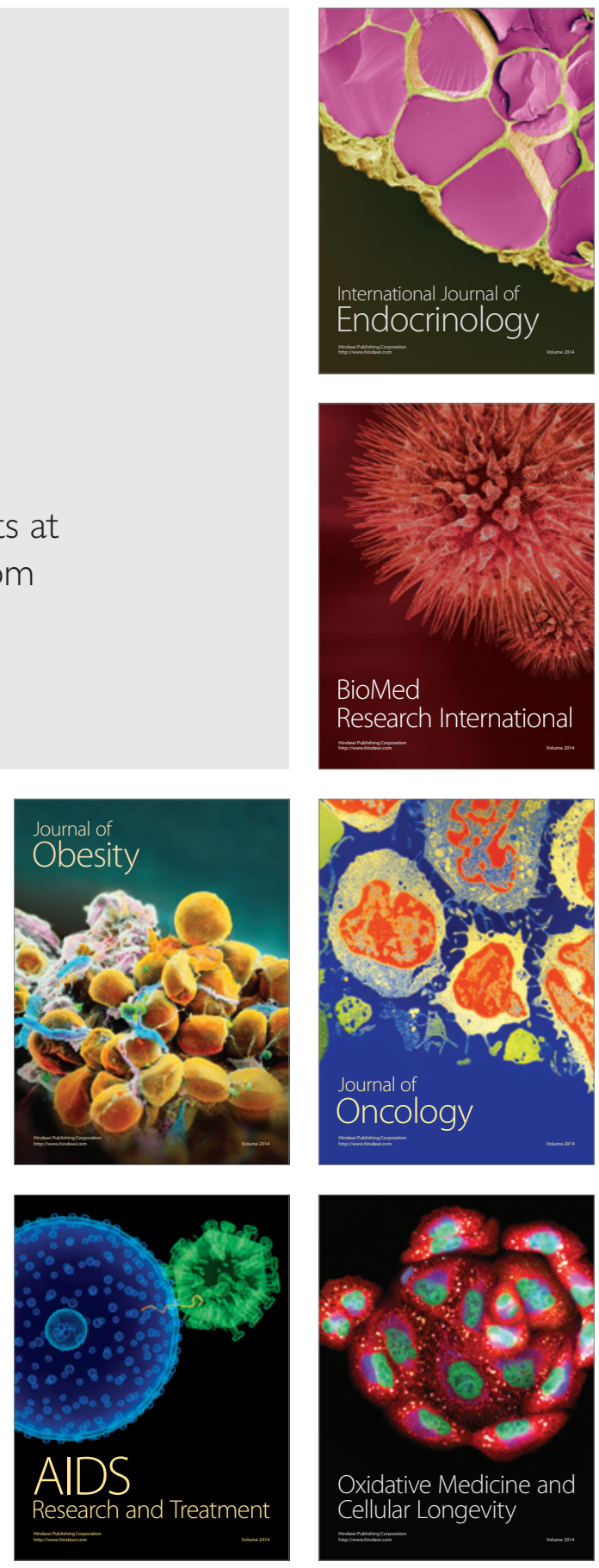